\title{
REMEDIAÇÃO DE SOLOS CONTAMINADOS COM FENANTRENO POR OXIDAÇÃO QUÍMICA IN SITU UTILIZANDO PERSULFATO DE SÓDIO ATIVADO COM ARGILA CHOCOLATE MODIFICADA
}

\author{
J. D. B. COSTA-FILHO ${ }^{1}$, V. M. A. MAGALHÃES ${ }^{1}$, G. P. $\operatorname{MENDES}^{1}$, M. M. G. VIANNA \\ e O. CHIAVONE-FILHO ${ }^{1}$ \\ ${ }^{1}$ Universidade Federal do Rio Grande do Norte, Departamento de Engenharia Química \\ ${ }^{2}$ Universidade Federal de São Paulo, Departamento de Engenharia Química \\ E-mail para contato: daladie@live.com
}

\begin{abstract}
RESUMO - O fenantreno é um hidrocarboneto policíclico aromático (HPA) constituído por três anéis benzênicos fundidos. Segundo a Agência de Proteção Ambiental dos Estados Unidos, este é classificado como um poluente prioritário devido à sua e importância industrial, toxicidade e persistência no meio ambiente. Uma técnica que tem se mostrado uma alternativa eficiente para o tratamento de poluentes orgânicos é a oxidação química. Este trabalho objetiva remediar solos contaminados com fenantreno por oxidação química in situ utilizando persulfato de sódio ativado por catálise heterogênea. Os experimentos foram realizados utilizando dois tipos de solo, denominados solo branco e solo vermelho. Para a síntese do catalisador, que tem como suporte a argila chocolate, foi utilizado o planejamento fatorial completo variando as concentrações de hidróxido de sódio, sulfato férrico e sulfato ferroso heptahidratado, totalizando 11 testes. Os 11 catalisadores foram, então, aplicados nos ensaios de oxidação em batelada por 48 horas para cada solo, a fim de avaliar o percentual de remoção do contaminante. Os resultados mostraram a eficiência dos catalisadores produzidos na ativação do oxidante no processo de oxidação química in situ para a degradação do fenantreno, sendo possível atingir cerca de $70 \%$ de remoção do contaminante.
\end{abstract}

\section{INTRODUÇÃO}

Acidentes provocados por vazamentos de hidrocarbonetos, além de consequências ambientais desastrosas, ocorrem em sua maioria em áreas urbanas densamente povoadas, resultando em riscos de explosões e incêndios em espaços confinados, no qual se destacam os sistemas subterrâneos de águas pluviais, esgoto, telefonia, metrô, eletrificação, subsolo de edificações, garagens, escavações, poços de água, entre outros (Favera, 2008).

\subsection{Contaminação por hidrocarbonetos policíclicos aromáticos}

Muitos pesquisadores têm publicado a respeito dos impactos adversos causados à saúde humana devido a contaminação por hidrocarbonetos policíclicos aromáticos (HPA) (Anyakora et al., 2011). A preocupação com a presença de HPAs no ambiente deve-se à possibilidade destes compostos reagirem diretamente ou após transformações metabólicas 
(ativação) com o DNA, tornando-se mutagênicos e carcinogênicos aos seres vivos. Os HPAs e seus derivados estão associados ao aumento de incidência de câncer de pulmão, intestino, fígado, pâncreas e de pele (Chakradeo et al., 1993). Apesar dos esforços dos órgãos reguladores, a contaminação por HPA não pode ser completamente eliminada, uma vez que a sua ocorrência está relacionada às atividades do cotidiano do homem (Anyakora et al., 2011).

\subsection{Técnicas de remediação de solo}

A oxidação química é um tipo de Processo Oxidativo Avançado (POA), muito aplicado na remediação de solos contaminados. Pode ser realizada, principalmente, de duas formas: no tratamento in situ e no tratamento ex situ. No tratamento in situ, a remediação é realizada no local da contaminação, sem que haja a necessidade de remoção do solo, processo conhecido por oxidação química in situ (ISCO). Em contrapartida, no tratamento ex situ, o solo é removido e tratado em um outro local. Os tratamentos in situ são frequentemente mais utilizados por apresentarem melhor custo-benefício quando comparado à remediação ex situ (Palmroth et al, 2006). A ISCO fundamenta-se, portanto, na injeção de oxidantes químicos em meios contaminados (solo, água subterrânea e sedimento), com a finalidade de degradar o contaminante através de reações químicas, convertendo-o em compostos inertes (Huling e Pivetz, 2006).

Uma forma relativamente nova de oxidante que tem sido investigada em escala de bancada é o persulfato $\left(\mathrm{S}_{2} \mathrm{O}_{8}{ }^{-2}\right)$. A ativação convencional deste oxidante, a partir da ativação por $\mathrm{Fe}^{2+}$, para geração de radicais sulfato $\left(\mathrm{SO}_{4} \bullet\right)$, ocorre em $\mathrm{pH}$ baixo. $\mathrm{O}$ meio ácido, portanto, pode alterar as características naturais do meio e afetar negativamente os sistemas existentes (Jorfi, 2013). Assim, a necessidade de trabalhar com um pH baixo pode ser considerada uma das desvantagens do método convencional (Silva, 2014). Entretanto, em processos usando catálise heterogênea, o ferro pode ser estabilizado no interior da estrutura porosa de um catalisador na forma de óxidos ou hidróxidos de ferro. Assim, é possível ativar o oxidante e produzir de forma eficaz os radicais provenientes do persulfato, sem a necessidade de ajuste do $\mathrm{pH}$ (Pouran et al. 2014).

O principal objetivo desta pesquisa é a remediação de dois solos contaminados com fenantreno, considerado um modelo de HPA, utilizando ISCO com sistema heterogêneo. Os objetivos específicos são: otimizar as condições de síntese do catalisador, de modo a obter um produto mais viável tecnicamente/economicamente; avaliar a eficiência deste catalisador na presença do oxidante persulfato de sódio para o tratamento dos solos; assim como, avaliar a influência da matéria orgânica e do ferro naturais dos solos no processo de remediação.

\section{METODOLOGIA}

\subsection{Coleta e Contaminação dos solos}

Objetivando investigar a influência do ferro e da matéria orgânica existentes no solo durante o POA, nos experimentos foram utilizados dois tipos de amostras diferentes de solo, identificadas como solo branco (SB) e solo vermelho (SV). Ambas foram coletadas no campus da Universidade Federal do Rio Grande do Norte (UFRN), na cidade de Natal/RN (Brasil), a aproximadamente $30 \mathrm{~cm}$ de profundidade. As propriedades dos solos são mostradas 
na Tabela 1. As amostras foram passadas por peneira de 2,38 mm (Mesh 8) para remoção de materiais grosseiros, homogeneizadas e armazenadas.

Tabela 1 - Propriedades dos solos.

\begin{tabular}{|c|c|c|}
\hline Itens analíticos & Solo Branco & Solo Vermelho \\
\hline $\mathrm{pH}$ & 5,70 & 5,56 \\
\hline Umidade (\%) & 1,45 & 2,91 \\
\hline $\begin{array}{c}\text { Teor de matéria orgânica } \\
(\mathrm{mg} / \mathrm{kg})\end{array}$ & 0,13 & 3,86 \\
\hline Ferro total $(\%)$ & 8,63 & 11,36 \\
\hline
\end{tabular}

A contaminação dos solos foi realizada em laboratório a uma concentração de $200 \mathrm{mg}$ de fenantreno (98\% da Sigma Aldrich) por $\mathrm{kg}$ de solo, sendo utilizado como solvente o hexano.

\subsection{Síntese do catalisador}

Nessa pesquisa, aplicou-se de um método inovador para a síntese do catalisador, o qual tem como suporte argila chocolate e como fase ativa óxidos e hidróxidos de ferro. Com a finalidade de avaliar as condições de preparo desses materiais, foi realizado um planejamento fatorial completo $2^{3}$, variando as concentrações de hidróxido de sódio $(\mathrm{NaOH})$ de 0,00 a 0,63 M, sulfato férrico $\left(\mathrm{Fe}_{2}\left(\mathrm{SO}_{4}\right)_{3}\right)$ de 80,00 a $274,50 \mathrm{~g} / \mathrm{L}$ e sulfato ferroso heptahidratado $\left(\mathrm{FeSO}_{4} .7 \mathrm{H}_{2} \mathrm{O}\right)$ de 38,05 a $150,00 \mathrm{~g} / \mathrm{L}$, com três pontos centrais, totalizando 11 ensaios.

A solução de ferro e a argila chocolate foram homogeneizadas em um reator de mistura intensa, onde a solução de $\mathrm{NaOH}$ foi gotejada durante uma hora. $\mathrm{O}$ material sintetizado foi colocado em estufa a $60{ }^{\circ} \mathrm{C}$ por 48 horas. Após seco, o catalisador foi desagregado com almofariz e pistilo, peneirado em uma peneira de 0,105 $\mathrm{mm}$ (Mesh 140) e, por fim, condicionado em frascos de vidro.

\subsection{Tratamento do solo contaminado}

A fim de investigar o comportamento dos catalisadores preparados previamente, foram realizados experimentos em batelada para o tratamento de solo contaminado com fenantreno por meio da oxidação química in situ utilizando o persulfato de sódio (PS).

Para os ensaios de remediação, em cada reator foram pesados 15 gramas de amostra de solo contaminado; 1,5 gramas de catalisador; e $30 \mathrm{~mL}$ de solução de PS na concentração de 41 g.L L $^{-1}$. Totalizando 22 ensaios, sendo 11 para o SV e 11 para o SB. Foram realizados ensaios controles de solo contaminado + água, solo contaminado + solução oxidante e solo contaminado + solução oxidante + argila chocolate bruta, nas mesmas condições de 
tratamento. Todos os experimentos foram realizados à temperatura ambiente, sem agitação e o tempo de reação foi de 48 horas.

\subsection{Extração e análise}

Para quantificar a contaminação residual, alíquotas de 2,5 gramas de amostra de solo foram retiradas de cada reator e adicionadas em vials de $40 \mathrm{~mL}$, juntamente com $10 \mathrm{~mL}$ de acetonitrila. Em seguida, os vials foram submetidos ao ultrassom durante 30 minutos para extração sólido-líquido. Após a extração, fez-se a filtração em filtros de $0,45 \mu \mathrm{m}$. O extrato foi adicionado em vials de 1,5 mL para análise em cromatógrafo líquido de alta eficiência acoplado com UV-Vísivel (HPLC-UV) da Shimadzu.

\section{RESULTADOS E DISCUSSÃO}

Os 11 catalisadores sintetizados com diferentes concentrações de $\mathrm{NaOH}, \mathrm{Fe}_{2}\left(\mathrm{SO}_{4}\right)_{3}$ e $\mathrm{FeSO}_{4} .7 \mathrm{H}_{2} \mathrm{O}$ foram analisados quanto a capacidade de ativação do persulfato de sódio, visando identificar qual deles iria apresentar o melhor percentual de remoção do contaminante para ambos os solos SB e SV, por meio da tecnologia de oxidação química in situ.

A Figura 1 mostra os resultados para o percentual de remoção do fenantreno, tanto para os ensaios controle (solo + água; solo + oxidante; solo + oxidante + argila bruta) quanto para os ensaios utilizando os 11 catalisadores, para os respectivos solos (SB e SV)

Figura 1 - Resultados para o percentual de remoção do fenantreno dos solos SB e SV para os ensaios controle apresentados no ponto zero ( $\square$ solo + água; solo + oxidante; $₫$ solo + oxidante + argila bruta) e para os 11 diferentes catalisadores.
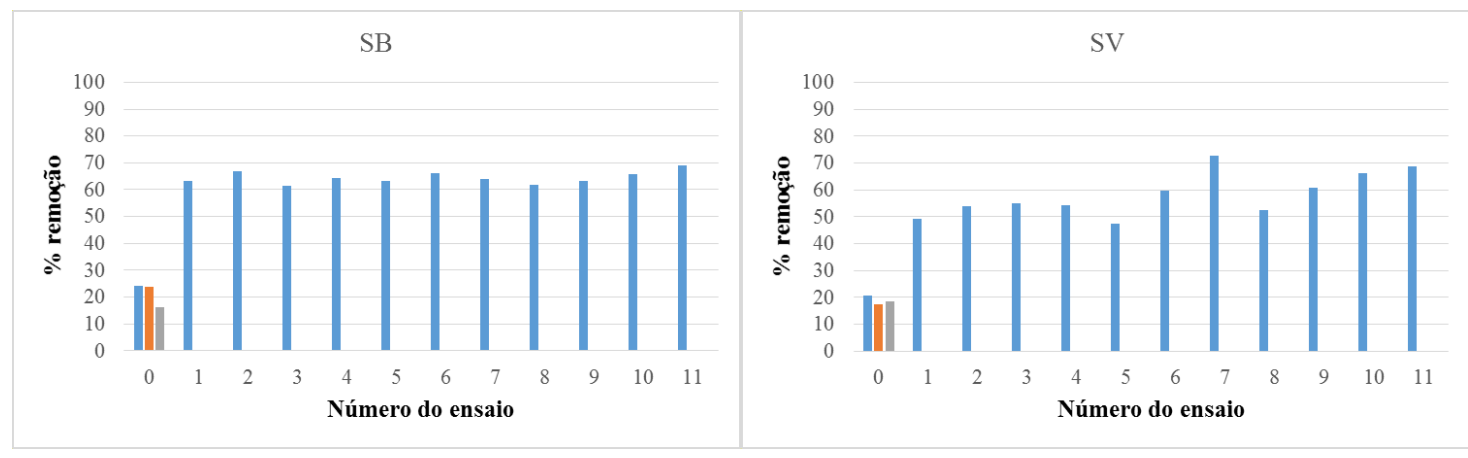

Na Figura 1, os ensaios controle são mostrados no ponto zero. O percentual de remoção em ambos os ensaios do controle solo + água é em torno de $20 \%$, isso ocorre devido à quantidade de fenantreno transferida naturalmente para a fase aquosa, efeito relacionado ao coeficiente de partição octanol-água ( $\log \mathrm{Kow}=4,62 \pm 0,01)$ do contaminante (Jonker, 2016). $\mathrm{O}$ controle solo + oxidante prova a necessidade da ativação do oxidante por meio de um catalisador, uma vez que o percentual de remoção obtido não variou consideravelmente em relação ao controle solo + água. E, por fim, os resultados para o controle solo + oxidante + argila bruta mostraram que a argila sem modificação não contribuiu para a ativação do oxidante. Além disso, para os ensaios referentes ao solo vermelho, a argila leva a uma redução no percentual de remoção do contaminante, reduzindo a eficiência do processo de oxidação. 
Não foi possível obter um modelo matemático e análises estatísticas referentes ao planejamento experimental aplicado, pois o trabalho em estudo está relacionado a um processo bastante variável por se tratar de reações em solo, meio muito complexo e com características incertas. Por isso, o planejamento serviu de base para análise da influência das variáveis em estudo (concentrações dos reagentes) sobre a resposta, percentual de remoção do fenantreno. Além de possibilitar a avaliação da eficiência de remoção do fenantreno pelo processo oxidativo avançado com persulfato de sódio ao utilizar os catalisadores preparados no estudo.

É possível observar que para os ensaios do solo branco na presença do oxidante, os resultados foram bem semelhantes em relação aos ensaios de 1 a 11 , permitindo um percentual de remoção entre 60 a $70 \%$ por meio da oxidação química. Os ensaios do solo vermelho com o persulfato de sódio, por sua vez, mostram que o catalisador 7 apresentou o maior percentual de remoção do fenantreno (aproximadamente 73\%). Contudo, este catalisador precisa de uma maior quantidade de reagentes para ser sintetizado quando comparado com o segundo melhor catalisador (11), que ainda atinge cerca de $70 \%$ de remoção.

Comparando os resultados obtidos em relação as características dos solos utilizados, esperava-se que o SV apresentasse melhor desempenho que o SB no processo de remediação, devido a maior quantidade de ferro presente na amostra, uma vez que a forma mais utilizada na ativação de oxidantes em aplicações ambientais é a partir de ferro (Shih et al., 2016). Entretanto, foi observado que não houve variação significativa na remoção do contaminante. Este fato pode ser justificado pela maior quantidade de matéria orgânica no solo vermelho, a qual é conhecida por interferir na oxidação química negativamente. Essa discussão está coerente com o descrito por Romero et al. (2011), que relata que a matéria orgânica natural do solo pode competir pelo oxidante durante a reação de oxidação química. Usman et al. (2012) afirma que o persulfato possui menor afinidade pela a matéria orgânica natural do solo, logo apresentará uma melhor eficiência em solos com maior teor de matéria orgânica quando comparado ao processo usando permanganato como oxidante. Tais fatos mostram que a matéria orgânica interfere nos processos oxidativos avançados.

\section{CONCLUSÃO}

A aplicação dos processos oxidativos avançados usando o oxidante persulfato de sódio com ativação por meio dos catalisadores sintetizados para o tratamento de solo contaminado com fenantreno apresentaram resultados significativos, uma vez que permite a degradação do contaminante. Os catalisadores têm como suporte a argila chocolate, um material que pode ser encontrado naturalmente no meio ambiente e de baixo custo. Além disso, por se tratar de catálise heterogênea, não há a necessidade de ajustar o pH, diferente do método convencional de ativação do persulfato pelo ferro, o qual necessita de $\mathrm{pH}$ ácido para a formação dos radicais, uma desvantagem nesse tipo de processo. Portanto, o uso da argila chocolate no processo de catálise heterogênia aplicado à ISCO pode ser considerado uma vantagem por não afetar as condições naturais do meio. Por fim, o catalisador 11 foi selecionado para ser utilizado em estudos posteriores, devido aos resultados expressivos quando comparado aos demais. 


\section{REFERÊNCIAS}

ANYAKORA, C.; COKER H.; ARBABI, M. Application of Polynuclear Aromatics hydrocarbons in chemical fingerprinting: The Niger Delta Case Study. Iran. J. Environ. Health Sci. Eng., v.8(1), p. 75-84,

CHAKRADEO, P.P. KAYAL, J.J.; BHIDE, S.V.; Effect of benzo(a)pireno and methyl(acetoxymethyl)nitrosamine on thymidine uptake and induction of aryl hydrocarbon hydroxylase activity in human fetal esophageal cell in culture. Cell. Biol. Int., 17(7), p. 671-676, 1993

FAVERA, C. H. D. Sites Contaminados por Hidrocarbonetos: Principais Técnicas de Remediação e Exemplo de Aplicação. Trabalho de Conclusão Curso de Engenharia Civil. Universidade Federal de Santa Maria, 2008.

HULING, S.; PIVETZ, B. Engineering Issue: In Situ Chemical Oxidation, USEPA 600/R06/072. U.S. EPA, Office of Research and Development, 2006.

JONKER M. T. O, Determining octanol-water partition coefficients for extremely hydrophobic chemicals by combining "slow stirring" and solid-phase microextraction. Envir. Chem., 35, p.1371-1377, 2016

JORFI, S.; REZAEE, A.; MOHEB-ALI, G.; JAAFARZADEH, N. Pyrene removal from contaminated soils by modified Fenton oxidation using iron nano particles. J. Environ. Health Sci. Eng., 1, p.11-17, 2013.

PALMROTH, M. R. R.; LANGWALDT, J. H.; AUNOLA, T. A.; GOI, A.; MUNSTER, U. PUHAKKA, J. A.; TUHKANEN, T. A. Effect of modified Fenton's reaction on mcrobial activity and removal of PAHs in creosote oil contaminated soil. Biodegradation, 17(2), p.29-39, 2006,

POURAN, S. R.; RAMAN, A. A. A.; DAUD, W. M. A. W. Review on the application of modified iron oxides as heterogeneous catalysts in Fenton reactions. J. Clean. Prod., 64, p.24-35, 2014,

ROMERO A., SANTOS A., CORDERO T., RODRÍGUEZ-MIRASOL J., ROSAS J. M., VICENTE F., Soil remediation by Fenton-like process: Phenol removal and soil organic matter modification. Chem. Eng. J. 170, p.36-43, 2011.

SHIH Y., BINH N. T., CHEN C. W., CHEN C. F., DONG C. Treatability assessment of polycyclic aromatic hydrocarbons contaminated marine sediments using permanganate, persulfate and Fenton oxidation processes. Chemosphere, 150, p. 294-303, 2016.

SILVA, C.K.O. Método Inovador de Ativação de Oxidantes no Tratamento de Poluentes Prioritários e Emergentes. Tese de Doutorado, Escola Politécnica, Engenharia Química, Universidade de São Paulo, 2014. 